\title{
具立-
}

\section{El cambio de paradigma tecnoeconómico y los nuevos escenarios profesionales. Crisis de los derechos laborales y nuevos riesgos emergentes}

\author{
Vicente Pedro Lafuente Pastor \\ Profesor Asociado de Derecho del Trabajo y de la \\ Seguridad Social de la Universidad de Zaragoza \\ vlafuent@unizar.es
}

Resumen: La «disrupción» de los modelos fabriles clásicos ha venido seguida de la «irrupción» digital, con un cúmulo de incertidumbres sobre los entornos económicos venideros. El cambio de paradigma manifestado por indicadores de flexibilización empresarial y primacía de la economía, presenta sinergias con la propia tecnificación en el trabajo. Ello tiene una relevancia clara en la aparición y agudización de nuevos riesgos laborales, pero trasciende sobre todo al cuestionamiento de algunos derechos laborales.

Examinándose sentencias recientes, datos estadísticos de relevancia, documentos de las instituciones y de los agentes sociales, y la doctrina más solvente, se 
describen y analizan diversas manifestaciones que acreditarían la mutación de los arquetipos laborales clásicos.

El nuevo paradigma tecno-económico está propiciando la dilución de los contornos de la prestación asalariada, una desvalorización del trabajo, incertidumbres cronificadas ligadas al mercado de trabajo que afectan al propio trabajador en su esfera personal y social. Aparecen simultáneamente nuevas enfermedades de la psique, anudadas al trabajo, bien por la maximización de su carga intelectual, bien por la falta de empleo, bien por su precarización sistémica.

Asoma también un nuevo escenario de «tecnoservilismo», ligado a la desvalorización general del hecho laboral, y a su subordinación a los avances tecnológicos. Por otra parte, los propios dispositivos tecnológicos como instrumentos de producción inciden en esa patología expandiendo e intensificando la potestad empresarial de vigilancia de la prestación laboral, frente a la salvaguarda de los derechos fundamentales de los trabajadores.

Frente a ello, la dignidad del trabajador debe descollar como valor jurídico y el Derecho del Trabajo erigirse como principal valedor del equilibrio entre los intereses en conflicto, haciendo compatible la tecnificación de la empresa con los derechos sociales.

Palabras clave: Paradigma tecno-económico, transformación de las relaciones laborales, tecnoservilismo, automatización, riesgos emergentes, dumping social.

\section{The techno-economic paradigm shift and the new professional scenarios. Crisis of labor rights and new emerging risks}

Abstract: Disruption' of the classical manufacturing models has been followed by the digital 'irruption', with considerable uncertainties over upcoming economic environments. The paradigm shift shown by indicators such as flexibility for companies and primacy of the economy, presents also synergies with the own technification at work. This issue is of clear relevance because of the development and intensification of new occupational risks, affecting mainly the questioning of some labor rights.

Considering recent judgments, relevant statistical data, institutions and social agents documents, and the most reliable doctrine, this Paper describes and analizes various indicators and events that themselves prove the mutation of the classic labor archetypes: 
The new techno-economic paradigm is leading to a dilution of the contours of the salaried labour, a devaluation of the work, chronic uncertainties linked to the labour market, impacting the worker in their personal and social sphere. Simultaneously appear new diseases of the psyche, closely connected to work, either by the maximization of their intellectual workload, either by lack of employment, either due to their systemic labour insecurity.

As a more significant result of the above, I underpin the thesis of a new scenario of 'techno-servility', associated with the general devaluation of the labor fact and with its subordination to the technological advances. Technological devices as production instruments, are causing the expansion and intensification of the business power and the work employees monitoring, against the safeguarding of the fundamental rights of workers.

To respond to this challenges, the dignity of the worker must prevail as a legal value and the labour law should channel its efforts in order to be the main defender of the balance between the interests in conflict, making compatible the technification of the company with social rights.

Key Words: Techno-economic paradigm, labour relations transformation, techno-servility, automation, emerging risks, social dumping. 



\section{El cambio de paradigma}

tecnoeconómico y los nuevos

escenarios profesionales.

Crisis de los derechos

Vicente Pedro Lafuente Pastor

\section{laborales y nuevos riesgos} emergentes

\section{INTRODUCCIÓN.}

A modo de introducción, comenzaré con un juicio de valor, arriesgado o al menos polémico. Considero que la mutación de la constitución social por el paradigma neoliberal o liberalista está provocando la aparición de un Derecho del Trabajo «invertido» o transmutado, en el que cada vez más intensamente prima la flexibilidad empresarial, paralelamente a la disminución de los estándares laborales.

El presente trabajo examina esta transformación de las relaciones laborales, anudada en parte a los cambios tecno-económicos, y analiza su proyección sobre el ámbito social y personal del trabajador, afectando a facetas y ámbitos de su vida esenciales, e incidiendo negativamente en su salud laboral. Por ello, esta perspectiva trasciende del marco de los riesgos laborales, que también se abordan, $y$, en concreto, de los riesgos emergentes vinculados al riesgo psicosocial, para hacer una crítica más amplia y holística de los cambios que se están produciendo en el mercado de trabajo. 
Es así como el concepto de riesgos emergentes cobra un significado anfibológico, como voz a la que voluntariamente se le dota de doble sentido. Pues no intento referirme sólo a las nuevas enfermedades de la psique, sino también a las consecuencias laborales y aun vitales, dimanantes de un marco de relaciones laborales progresivamente alejado de los patrones clásicos, con difuminación de sus rasgos esenciales.

Asistimos, de esta manera, a un proceso de desconsolidación del Derecho del Trabajo tuitivo, con una creciente apariencia de fragilidad de sus estructuras tradicionales. Un marco industrial con incertidumbres, en el que nuevas formas de producción se superponen con rapidez a las tradicionales. El trabajo con derechos parece perder consistencia, hablándose incluso de su progresiva «licuación». Embates de la economía para buscar una competitividad extrema basada en el precio degeneran en fenómenos de dumping social, e incluso de fuga del marco jurídico del Derecho del Trabajo.

Añadiéndose a este cambio de paradigma, la quiebra de los modelos fabriles «fordianos» se ha solapado con la infiltración de la tecnificación digital y la percepción de una vacilación sistémica sobre el rol que va a desempeñar el trabajador asalariado en este ámbito de adaptación permanente a las tecnologías masificadas de innovación y comunicación.

De este modo, en el presente Estudio se abordan algunas cuestiones de interés: en primer lugar, alentados por la reforma laboral de febrero de 2012, contemplamos cómo proliferan fenómenos de externalización masiva de la producción para abaratar costes. En segundo lugar, figuras de configuración dudosa, ligadas al trabajo autónomo y al trabajo «a proyecto» o en función del resultado, sustituyen incipientemente los perfiles clásicos del trabajo asalariado. En tercer lugar, los derechos a la intimidad informática ceden con la intromisión masiva de las nuevas tecnologías en los modos de producción.

Adicionalmente, parece una hipótesis de trabajo que debe evaluarse que la automatización y robotización de los procesos genera más valor añadido a las empresas, pero a costa de disminuir significativamente la aportación de la mano de obra, sobre todo de la menos cualificada o más serializada. 
Por otra parte, al socaire de las conexiones aplicativas de las TIC (Tecnologías de la Información y de la Comunicación), se están produciendo fenómenos de extrema afinación del control de la actividad laboral, y reacciones consiguientes de defensa de los derechos de la personalidad del trabajador: la videovigilancia, la cibervigilancia, las expectativas de confidencialidad, el derecho a la desconexión, el habeas data, el esquirolaje tecnológico, son solo una muestra de ello.

No puede cuestionarse el que estos constructos suponen ya en ocasiones un sesgo de sobreexplotación sutil que está aflorando en una «sociedad del cansancio», en expresión del filósofo alemán de origen coreano, Byung-Chul Han.

\section{UN ESCENARIO INDUSTRIAL CON INTERROGANTES.}

La perspectiva de un proceso productivo en el que domine la ciberindustria presenta, al menos, tres grandes cuestiones aplicativas: la posible aparición de un desempleo estructural, la nueva alfabetización básica requerida para acceder al mercado laboral, que esta vez será de carácter digital y, consiguientemente, la polaridad laboral aguda que se planteará entre las personas duchas y las inexpertas en las habilidades y competencias digitales, superponiéndose a la actual que diferencia los trabajadores con contratos fijos y los que tienen contratos temporales.

Así, no parece descabellado conjeturar que los empleos que genere la industria 4.0 pueden no ser capaces de absorber los puestos de trabajo redundantes u obsoletos, que cubrirían máquinas pseudo-inteligentes. La globalización y las nuevas tecnologías de la información y de la comunicación (TIC) comportarían aumentos acelerados de la productividad, ligados a un desempleo estructural, tal y como sostiene Jeremy Rifkin en «El fin del trabajo".

La empresa que no invierta en estas nuevas tecnologías, sin embargo, parece condenada a la obsolescencia. Por otra parte, la automatización de procesos acelera los tiempos de producción y la gestión comercial, pero también prioriza procesos de «reingenierización» basados en la robótica y en la informática, por lo que esta expulsión del mercado de trabajo podría afectar 
incluso a estratos amplios de trabajadores cualificados, mandos intermedios y profesiones liberales.

La implantación de la automatización, además, posiblemente desemboque en organizaciones más estructuradas y jerarquizadas, puesto que la mayor información y conocimiento que se deriva de la manipulación de los datos digitalizados serviría, no para democratizar liderazgos y hacer estructuras más participativas, sino para acentuar el poder de dirección empresarial con un control más estrecho sobre la prestación laboral.

La interdisciplinariedad para ser competitivo en el mundo del trabajo será casi obligada, y en todo caso propiciará una nueva alfabetización mediática. Se incrementarán los niveles de educación superior como medio para acceder a un empleo de alta tecnología. Se generará sobrecualificación académica y profesional, lo que permitirá a las empresas disponer de una demanda de trabajo numerosa y expectante de suma valía pero con una oferta limitada.

La polarización o dualidad laboral en relación con el contingente no alfabetizado digitalmente será muy acusada. Los empleos que requieran alta tecnología serán más resistentes a los periodos de crisis, al ser más productivos.

Respecto al segmento inferior, los salarios serán muy bajos, porque deberán competir con el coste de las máquinas, que harán esos trabajos monótonos o repetitivos y las tareas codificables.

\section{NUEVAS FORMAS DE PRODUCCIÓN Y RIESGOS EMERGENTES.}

En la Unión Europea, según expone el Informe de la OIT de 2017 «Trabajar en cualquier momento y en cualquier lugar: consecuencias en el ámbito laboral», ya un $17 \%$ de los trabajadores desempeña la actividad laboral en algún tipo de interacción teletrabajo-TIC y tecnologías móviles.

Las ventajas en no desplazamientos y en autonomía, así como en flexibilidad, conciliación, reducción del espacio de oficina y costes asociados, se compensa con la tendencia a trabajar más horas, con el solapamiento creciente entre el trabajo remunerado y la vida familiar, y con la propia intensificación del trabajo, que 
generan niveles adicionales de estrés. Los lindes entre la vida laboral y la personal se desdibujan.

Pero las conclusiones son necesariamente ambivalentes, siendo importante saber si ese trabajo a distancia sustituye o complementa al trabajo de oficina. La desaparición del concepto de horas extraordinarias, la dificultad de supervisión en materia de seguridad y salud laboral, la disipación de los tiempos de descanso y los impedimentos para la formación, son obstáculos añadidos.

En esta tesitura, se avanzan nuevos riesgos laborales, fundamentalmente de carácter psicosocial, que tendrán una importancia superior a los tradicionales ligados a las condiciones materiales de trabajo. Serán una constante en una ecología empresarial basada en la competitividad extrema, en el aislamiento del trabajador y en su exclusión de la interacción social del grupo de trabajo. El estrés de origen laboral emerge como principal riesgo que debe valorarse, anudado a los nuevos modos de producción tecnificada. No son meros augurios. La Segunda Encuesta europea de empresas sobre riesgos nuevos y emergentes (ESENER-2), confeccionada por la Agencia Europea para la Seguridad y Salud en el Trabajo, ya avanzaba en 2014 que «los lugares de trabajo en Europa evolucionan constantemente a consecuencia de los cambios económicos y sociales». Estos cambios resultan especialmente difíciles y provocan enfermedades de la psique, dado que, además, los trabajadores con 55 años o más representaban ya en ese año, en el $21 \%$ de las empresas de la Europa de los Veintiocho, el $25 \%$ de su plantilla, Los desbordamientos de los recursos para afrontar las nuevas demandas y la falta de adaptabilidad a las nuevas circunstancias se constatan como más frecuentes en los trabajadores veteranos. Además, también se decía en la encuesta ESENER-2 que los factores de origen psicosocial son más difíciles de gestionar que los de otro tipo, careciéndose de la información precisa para abordar estos riesgos de una manera eficaz.

Como otra manifestación de riesgos laborales provocados por las nuevas condiciones de trabajo tecnificadas, se hace evidente que los nuevos dispositivos electrónicos que la empresa pone a disposición del trabajador permiten que éste no esté desconectado en ningún momento de su trabajo. Ello ocasiona que 
los empleados adolezcan de un rendimiento laboral perfectible, debido al alargamiento del tiempo de exposición y al agotamiento intelectual causado por una disponibilidad indefinida. Lo que está ocasionando ya graves problemas de salud debido al estrés y al sobreesfuerzo mental, por la falta citada de una desconexión nítida entre trabajo y vida personal, lo que a su vez repercute en la proliferación de hábitos de vida personal no saludables e incluso de adicciones que sirven de sedante de la presión del trabajo.

Lo que trasciende, en definitiva, del ámbito estricto de la prevención de riesgos laborales, ya que el origen hay que buscarlo en los nuevos procesos productivos y en el paradigma liberalista de relaciones laborales. El empleador ya no necesita estrictamente ejercer la palanca de la explotación o alienación «estricto sensu». El propio trabajador, al que se le dota de una autonomía aparentemente amplísima, se autodisciplina para maximizar la eficiencia en el trabajo hasta extremos patológicos, produciendo el síndrome de agotamiento ocupacional y la percepción periódica de fracaso, ligados a sintomatologías mixtas de ansiedad y depresión. Se origina de este modo lo que la psiquiatría denomina neurosis laboral, como respuesta a la exposición del trabajador a un riesgo que provoca estrés psicosocial y que ya se recogía en la Ley 16.744 de Chile sobre Accidentes y Enfermedades Profesionales de 1968 al aludir a los trabajos que se exponen a un riesgo de tensión psíquica excesiva.

Lo más relevante, por ser la tendencia más reciente, es que esa extenuación productiva trae causa parcialmente en la indiferenciación del tiempo y del lugar físico para el trabajo. Lo que difícilmente puede llevarse a cabo sin una interferencia tóxica de éste en la vida privada y de ocio del trabajador, que ya no se configura como dependiente o prestador de servicios por cuenta ajena sino como «homo laborans», al que no se le pide el rendimiento normal de la prestación laboral sino máxima y constante «productividad.

De ello deriva su auto-explotación profesional en un mercado descarnadamente competitivo y, además, de exposición y transparencia absoluta para el trabajador. Las hechuras de su propia actividad laboral le son radiografiadas en tiempo real mediante los dispositivos electrónicos, herramientas ya básicas del trabajo, puestas a su disposición por la empresa. 


\section{ENTORNOS SOCIOECONÓMICOS DE LA SOCIEDAD POSTINDUSTRIAL.}

Por otra parte, nuevas realidades provenientes de los entornos socioeconómicos están aflorando, incidiendo en las formas de trabajar y marcando las sendas del futuro del trabajo. Resumamos sucintamente los puntos clave:

Primero, parece obvio pensar que en el presente siglo el mayor suministrador de trabajo para las personas será paradójicamente un sector tecnológico que amortizará, sin embargo, muchos de los puestos de trabajo existentes. En este contexto, se han propuesto todo tipo de soluciones, algunas interesantes, como el establecimiento de un nuevo contrato con la sociedad civil basado en la economía social, también denominado «tercer sector», que precisaría de un cambio sustantivo en la fiscalidad (J. Rifkin, cit.).

Segundo, el tecnoglobalismo se integra con un rango inabordable de tipologías tecnificadas que parecen ser además la punta de un iceberg de otras magnitudes más complejas. Transformará los modelos de negocio, generará la creación de muchas empresas pero se cerrarán otras tantas con un potencial disruptivo indudable. Los grandes gigantes de estos procesos son pocos y el riesgo de oligopolio de estos operadores, evidente.

Tercero, las personas no son mercancías (ya lo exponía Sinzheimer en tiempos de la República de Weimar) y se requiere una reflexión sobre cómo se sustituirán las rentas de trabajo y se redistribuirá la riqueza. No puede pedirse a los robots que paguen impuestos pero sí que tributen adecuadamente las empresas que tengan beneficios maximizados como consecuencia de la concentración empresarial, de las rentas de la tecnología y del coste marginal cero de la digitalización.

Cuarto, habrá menos empleo y diferente, esa parece ser la tónica futura. La formación será de nuevo imprescindible para no perder definitivamente la senda de la empleabilidad.

Quinto, el autoempleo, motivado por la propia exigencia de la empresa cliente y por los estados de necesidad del trabajador, así como la prestación laboral a tiempo flexible y sin corsés para el cliente-empresario, ya se está generalizando. 
Sexto, consecuencia de la falta de conexión con el lugar de trabajo, a menudo los factores de riesgos para la salud del trabajador serán indetectables y no podrán ser evaluados. A título de ejemplo, es palmario que una evaluación de riesgos en el domicilio del trabajador presenta dificultades añadidas no bien resueltas en el actual marco normativo de la prevención de riesgos.

\section{LA LICUACIÓN DEL TRABAJO.}

Un aspecto sin duda capital es el conflicto sistémico entre los modos de producción tecnificados y los derechos fundamentales. Es una realidad presente la afectación práctica de la tecnificación en los derechos de la personalidad, como los derechos de intimidad o protección de los derechos de imagen. Esta colusión puede adquirir tintes más acusados en el futuro postindustrial. Por ello, se está hablando de que este paradigma digitalizador traiga como resultado una progresiva licuación de los derechos, acentuando además esta tendencia la hiperconectividad entre trabajo y ámbito privado.

Las reglas jurídicas parecen perder su valor ante el ensanchamiento hipertrófico y acelerado de las aplicaciones técnicas, inmediatamente socializadas. Se difumina la aprehensión de los derechos en estos contextos de «sociedad compartida y líquida», en expresión de Ziygmun Bauman, caracterizada por la precariedad e incertidumbre, en el que los logros profesionales nunca se consolidan y son crecientemente marginales.

Por ello, el conflicto entre instituciones está servido. El Derecho del Trabajo no puede renunciar a la transacción de ese conflicto propio de la sociedad civil entre grupos de intereses ni abandonarse a los flujos erráticos o constrictivos de los derechos de la personalidad, propios de los nuevos rumbos digitalizadores de la producción. Téngase en cuenta que la creciente autonomía en la prestación laboral, fruto de los nuevos dispositivos y procesos computerizados, incide sutil pero eficazmente en los mecanismos de control de dicha actividad, en los que la manipulación de los datos es sencilla, afectando a la privacidad del trabajador. 


\section{LA HUIDA DEL DERECHO DEL TRABAJO.}

Ya en el pasado, la doctrina alertaba de los peligros de una huida del Derecho del Trabajo, y se afirmaba que esta patología no era sólo una perversión sino también, parcialmente, una reacción contra la aplicación de reglas disfuncionales restrictivas de esa necesidad de mudanza y de adaptación a los cambios productivos. En la actualidad, esta fuga del Derecho laboral se hace más palpable y general, percibiéndose cierta incapacidad de la disciplina para embridar fenómenos anudados a la ciberindustria y a la socialización de las redes y dispositivos electrónicos.

Falta un debate serio sobre un problema conexo con esta dualidad. Como válvula de escape, asistimos desde hace décadas a comportamientos dudosos, cuando no claramente defraudatorios: contratación de «falsos autónomos» para evitar cargas sociales e indemnizaciones por despido, generalización de contratos temporales acausales, descentralización productiva masiva con el único referente del precio y altos niveles de economía sumergida.

Prima la indisimulada tendencia a sustituir el contrato de trabajo por el de prestación de servicios o la aparición de figuras híbridas o confusas que podríamos definir como de cuasi-asalariados. Son, en definitiva, trabajadores «contingentes», huérfanos de carrera profesional y de derechos consolidados.

Un estudio de la empresa de software «Intuit» asegura que en 2020 más de un $40 \%$ de la población laboral estadounidense estará formada por estos trabajadores, denominados "contingentes». Hablamos de unos sesenta millones de personas. Pero ello no es ninguna panacea, antes bien, es una manifestación de la degradación de las relaciones laborales, ante la cual el Derecho del Trabajo no puede adoptar meras actitudes «tancredistas» o reactivas.

Por otro lado, ya actualmente en el panorama laboral español asistimos a fenómenos ligados al dumping social mediante el uso de herramientas jurídicas disponibles para el empleador en forma de externalización masiva de la mano de obra, fundada en causas exclusivas de obtención de un mayor beneficio empresarial. Lo más inquietante es, sin embargo, el refrendo judicial a dichas políticas degradatorias del estatuto asalariado. 
Así, la Sentencia del Tribunal Supremo de 20 de noviembre de 2015, RCUD 104/2015, en el caso Meliá Hoteles, versa sobre un despido colectivo basado en causas organizativas que se califica como ajustado a derecho. Se externaliza el servicio de limpieza de dos hoteles de la cadena, compuesto por mujeres en un $96 \%$. Lo cierto es que se suscitan temas capitales como el fenómeno del dumping social.

La resolución judicial avala la procedencia de una externalización ilimitada basada simplemente en la expectativa de mayor ganancia empresarial, que los votos particulares de la sentencia califican de ilícita por abusiva, pues estaríamos en los umbrales de una «externalización sin límites, que sólo puede ser calificada de ilícita por abusiva, pues se trata de una medida que conduce, en el caso, a la precariedad de las condiciones laborales, al denominado dumping social, cuanto menos del salario». Ya que el ahorro que consigue la empresa es a costa de un descenso de hasta el 50\% de los salarios de las trabajadoras de la subcontrata.

Pero es que la descodificación de las garantías del Derecho del Trabajo tampoco es eficaz en una sociedad avanzada del conocimiento. Eva Rimbau-Gilabert y Vasileios Myrthianos han demostrado que formas de trabajo no permanentes en el empleo, como los trabajos contingentes, o la externalización de la prestación laboral individual, se correlaciona con una menor productividad del trabajo en las empresas de servicios intensivas en conocimiento, que cobrarán importancia creciente en el futuro postindustrial.

En cualquier caso, esta evasión de las reglas laborales genera como secuela otro fenómeno, el de la intensificación de la actual dualidad laboral y brecha social, y se acentuará todavía más en el momento en que los trabajos se segmenten entre aquéllos necesarios para hacer funcionar las máquinas, y aquéllos intercambiables con las máquinas. Los segundos sólo podrán ser productivos si su coste es similar al de aquéllas.

\section{LA DEBILIDAD DE LA REACCIÓN DEL DERECHO DEL TRABAJO. EL DUMPING SOCIAL.}

Abundando en lo dicho, contemplamos como ya actualmente, la desvalorización del empleo asalariado está perjudicando seria- 
mente al tejido productivo, incluyendo a las empresas cumplidoras de la legalidad vigente, que no pueden competir en igualdad de condiciones con aquéllas que utilizan mecanismos de dumping social para reducir costes y acaparar mayor cuota de mercado.

La reacción del legislador ante este escenario de escapismo laboral ha sido tardía. El Partido Socialista presentó, por segunda vez, el 9 de septiembre de 2016 una Proposición de Ley de modificación del artículo 42.1 del Estatuto de los Trabajadores para garantizar la igualdad en las condiciones laborales de los trabajadores subcontratados. La iniciativa pretende regular controles que impidan el abuso y la competencia desleal, basados en la degradación de las condiciones laborales y en la rebaja de la calidad en la prestación de servicios. Esa competencia desleal frecuentemente adopta la forma de rebaja salarial, pero también de reducción drástica de los estándares de seguridad y salud. Por ello, acertadamente, la Proposición pretende que los trabajadores que presten servicios en un mismo sector tengan garantizado el mismo salario y las mismas condiciones de trabajo.

Esta situación ha sido también denunciada por instituciones laborales representativas de algunos sectores productivos. En el Informe de situación del sector de la construcción del Principado de Asturias, del año 2015, suscrito por los agentes sociales y la patronal, se ponen de manifiesto problemas ya estructurales de ilegalidad, fraude, competencia desleal y economía sumergida en obras de construcción. Se denuncia el incumplimiento de la Ley reguladora de la Subcontratación en el sector de la Construcción, el incorrecto encuadramiento del convenio colectivo, buscando salarios inferiores y la admisión de ofertas en concursos públicos con costes salariales mínimos inferiores a los estipulados en los convenios colectivos. Se reprocha la incorporación de falsos trabajadores autónomos en las obras con coste inferior al que tendría un trabajador por cuenta ajena al que se la aplicara el convenio colectivo.

Es significativo, en este sentido, el aumento exponencial de trabajadores autónomos, incluso en el periodo pasado de crisis, frente a la destrucción masiva de empleo asalariado. En Aragón tenemos un ejemplo muy expresivo, también en el sector de la construcción. 


\begin{tabular}{|c|c|c|c|}
\hline \multicolumn{4}{|c|}{ ARAGÓN. AFILIADOS EN EL SECTOR DE LA CONSTRUCCIÓN } \\
\hline & MARZO 2017 & MARZO 2007 & VARIACIÓN \% \\
\hline ASALARIADOS (RG) & 20.129 & 53.734 & $-62,5 \%$ \\
\hline TRABAJADORES AUTÓNOMOS & 12.026 & 10.225 & $17,6 \%$ \\
\hline TOTAL & 32.155 & 63.959 & $-49,7 \%$ \\
\hline PORCENTAJE DE TA & $37,4 \%$ & $16 \%$ & \\
\hline
\end{tabular}

Cuadro de elaboración propia. Datos procedentes de la Tesorería de la Seguridad Social.

Comparando las cifras de afiliados a la Seguridad Social en dos momentos muy diferentes, el de marzo de 2017, con el mismo mes de 2007, diez años atrás, en los umbrales del comienzo de la crisis, comprobamos que el número de asalariados en el sector se ha reducido drásticamente, en un $62,5 \%$. Sorprendentemente, ha crecido el número de trabajadores autónomos, nada menos que en torno a un 18\%. Ello quiere decir que el empleo autónomo ha crecido con independencia del colapso constatado de la actividad.

Sin duda, las condiciones de trabajo se han precarizado extraordinariamente, pero los instrumentos jurídicos de sustentación de las relaciones laborales en el sector se han mantenido pese a las adversidades, y el Convenio General de la Construcción, la Fundación Laboral de la Construcción o documentos como la Tarjeta Profesional de la Construcción son ejemplos y manifestaciones de negociación colectiva responsable. Por ello, la desvalorización de la fuerza del trabajo ha escogido en el sector de la construcción la fuga del Derecho Laboral, y su inserción en el trabajo autónomo, en ocasiones teñido de irregularidad, al disfrazar un trabajo asalariado encubierto.

Como corolario, la crisis está empujando a la mano de obra, en primer lugar, a la economía sumergida o informal. Eurostat sostiene que en España ésta representa el 18\% del PIB, ocupando a 400.000 personas. En segundo lugar, prolifera el encuadramiento irregular y desplazamiento a convenios colectivos sin regulaciones en materia de formación, prevención de riesgos o asistencia social, y que cuenten además con tablas salariales de importes reducidos. 
Añadido a esta circunstancia, la reforma laboral de 2012 materializa la prioridad absoluta e incondicionada del convenio de empresa, utilizado como instrumento de reducción de costes laborales por empresas intensivas de mano de obra que ofrecen sus servicios a las empresas principales como contratistas o subcontratistas. Es cierto que es un principio plausible la adaptación de las condiciones laborales, especialmente salariales, a la realidad de las empresas, pero este principio de primacía no debiera utilizarse en fraude de ley sólo para abaratar precios y favorecer una competencia injusta y desleal.

\section{LAS CAUSAS MÚLTIPLES DEL NO EMPLEO.}

No obstante, debe hacerse un ejercicio de honestidad y reconocer que la causa del paro estructural en España, al menos hasta la fecha, no obedece a la aparición de las nuevas tecnologías, tampoco de forma sustancial a las ineficiencias regulatorias del mercado de trabajo. La historia reciente de la economía española nos demuestra que este desempleo ha estado más vinculado a sistemas productivos raquíticos en cuanto a inversiones en innovación y desarrollo, a la endeblez de una economía sustentada en sectores auxiliares de poco valor añadido y de carácter estacional, y a la crisis de financiarización global y especulativa.

Contrariamente, parece necesario para fortalecer la economía luchar contra colusiones del mercado, vigorizando simultáneamente una política proactiva de diálogo social y un marco democrático de negociación colectiva. Así, estudios del economista Ordan Brennan, del Centro de Políticas Alternativas de Canadá, sustentan la tesis, investigando la relación entre desaceleración del crecimiento económico y el crecimiento de las desigualdades en Canadá y Estados Unidos, que el incremento de la concentración empresarial y el debilitamiento del poder sindical han correlacionado históricamente con el aumento de las desigualdades. Cuando el poder de negociación de los trabajadores ha sido mayor, la riqueza se ha distribuido de forma más equitativa y la renta salarial ha tenido un mayor peso en la economía. Como consecuencia, ha habido un mayor crecimiento económico, se ha potenciado la inversión productiva, se ha creado más empleo y éste ha sido de más calidad. 
Por ello, el Derecho del Trabajo debe reestablecer los consensos en el mundo del trabajo, y la política económica favorecer la competencia y obstaculizar la formación de cárteles y oligopolios.

\section{RIESGOS EMERGENTES Y RIESGOS ANTIGUOS.}

En fin, son de sobra conocidos riesgos cada vez menos emergentes y más consolidados.

Las estructuras de las organizaciones son cada vez más maleables e invertebradas y parecen exigir acuerdos laborales muy flexibles, pudiendo el convenio colectivo degenerar en instrumento o mera comparsa de las políticas empresariales de adaptación a los nuevos cambios. Se generaliza la precarización, los turnos, los trabajos a demanda y de cero horas, con disponibilidad total. Los horarios flexibles sirven para moldear la producción de la empresa, no para incrementar la calidad de vida laboral de los empleados. Los trabajos a tiempo parcial obedecen a esa misma necesidad de flexibilidad empresarial y no a la conciliación querida por el trabajador con su vida personal.

El envejecimiento de la población laboral hace que la exposición a riesgos laborales sea un hecho. A partir de 55 años, dice la Comisión Europea, hay más probabilidad de sufrir un accidente grave. Pasaremos de 75 a 135 de millones de personas mayores de 65 años en la UE en 2050, según informa Eurostat, y el 36\% de la población española tendrá más de 65 años. Este colectivo, además, adolece de una mayor dificultad para asimilar los avances tecnológicos. El reciclado continuo de las habilidades y conocimientos para consolidar la aptitud laboral debe ser un objetivo esencial.

Hay un lugar común que pone la causa de la desconfianza de los jóvenes en el mundo de trabajo convencional en su consideración de nativos digitales y en su desprecio a la constricción en un patrón laboral clásico de horarios, presencia o dependencia general de instrucciones de trabajo. Pero es lo cierto que el recelo experimentado lo es a las manifestaciones patógenas de ese modelo en forma de precarización elevada, magros salarios y explotación laboral. No estamos dando oportunidades laborales dignas a las generaciones mejor preparadas profesionalmente de la historia de nuestro país. 
Como consecuencia de la precarización de las condiciones laborales, emerge una dimensión económica de la prevención de riesgos que debe ponderar los costes de la no calidad en el empleo, la angustia de los trabajadores pobres, que carecen de la mínima estabilidad laboral, la incertidumbre laboral, y el propio desempleo como post-factor psicosocial de riesgo.

No podemos obviar, respecto al reto de la tecnificación, sus connotaciones de mejor conocimiento del mercado, de simplificación de procesos, de ahorro de costes, de mejora continua y de innovación, y su reverso de amortización de mano de obra, y de riesgos emergentes ligados a la actividad que se desarrolle: estrés cronificado, fatiga mental, falta de interacción social, demanda creciente de concentración con repercusiones altas de los errores, no-expectativas y «rutinización» en la carrera laboral, y competitividad extrema y globalizada.

\section{EL DERECHO DE DESCONEXIÓN DIGITAL VS. TECNOSERVILISMO.}

Con carácter general, la actitud doctrinal de los valedores del Derecho del Trabajo suele ser tardía frente a las agitaciones constantes y los acelerones históricos en las mutaciones de los cambios productivos.

El derecho a la desconexión digital está regulado finalmente en el Derecho Francés a través de la Loi Travail Nº 2016-1088, de 8 de agosto, reivindicando el derecho al descanso del trabajador frente a los imperativos de respuesta de los dispositivos móviles puestos a disposición por la empresa. Es una respuesta, al menos, a los excesos del uso de los medios digitales en el ámbito laboral.

Como contraste decepcionante, en España, la única referencia normativa en la última reforma laboral de 2012 ha consistido en un cambio cosmético de denominación del antiguo contrato a domicilio por el de a distancia, en el artículo 13 del Estatuto de los Trabajadores, sin una modificación sustancial que adapte su contenido al teletrabajo basado en las TIC.

En cualquier caso, en nuestro país los derechos a la intimidad informática no sólo no se están reforzando con esta intromisión masiva de las nuevas tecnologías en los modos de producción, sino que se han convertido en dispositivo apto para instaurar un 
tecnoservilismo de nuevo cuño, que hasta la fecha no está encontrando los límites infranqueables que deben demandarse por parte del legislador y de los tribunales.

Herramientas intangibles, de conformación licuosa, como los registros informáticos, las páginas temporales, las redes sociales o los correos electrónicos, y la generalización de la vigilancia de cámaras y dispositivos de grabación, aseguran la existencia de un «trabajador transparente», muy vulnerable en el ámbito disciplinario, así como una hiperactividad potencial del derecho de corrección empresarial, con la amplificación disponible de sus medios de control digitalizados.

La reforma laboral de 2012, a pesar de su ambicioso proyecto de remozar nuestro sistema de relaciones laborales, hace tabla rasa de cualquier intento de proponer medidas que coadyuven a la consecución de un cambio de modelo productivo basado en pilares tales como la innovación, la industrialización, la productividad interna, la gestión avanzada y la satisfacción laboral.

Paralelamente, sin ninguna de sus ventajas, estamos adquiriendo algunas de las patologías más destacadas de la nueva sociedad postindustrial, así, la aparición de enfermedades de trabajo como el "tecnoestrés", que nacen como consecuencia la utilización de dispositivos tecnológicos puestos a disposición por la empresa. En el seno de una competitividad hipertrofiada, la lealtad en el servicio por el trabajador debe ser total, configurándose una disponibilidad máxima hacia la empresa, que invade de forma permanente el tiempo de ocio y personal. No suele haber recompensas para esta elongación de la prestación laboral, que se cuenta como obligación ínsita al contrato de trabajo y sí, en cambio, una incertidumbre extrema en el devenir profesional, que tácitamente se hace depender de una actitud incondicional y acrítica del trabajador con esta situación.

\section{EL ABUSO TECNOLÓGICO Y LA REACCIÓN JUDICIAL.}

¿Cuál es la reacción de los tribunales ante la progresiva intromisión del poder de dirección en los derechos constitucionales del trabajador?

En algún caso, se han dibujado límites precisos a una hipotética potestad arbitraria del empresario de interferir en la vida 
personal del trabajador. La Sentencia del Tribunal Supremo 21 septiembre 2015, RC 259/2014, en el caso Unísono Soluciones del Negocio, establece como abusiva la cláusula que en el contrato de trabajo exige que el trabajador proporcione voluntariamente a la empresa el número de teléfono móvil y su cuenta de correo electrónico personal.

Por su parte, la Sentencia del Tribunal Superior de Justicia de Cataluña núm. 3613/2013, de 23 mayo, en el caso del Acelerómetro de Schindler, debate los límites al poder de dirección y también el derecho a la intimidad personal y a la propia imagen, declarando que la adopción de medidas de vigilancia y control por parte del empresario consistentes en la instalación de un acelerómetro en los teléfonos móviles de los trabajadores de la sección de mantenimiento, constituye una medida desproporcionada. El acelerómetro es un aparato que capta el movimiento o la ausencia del mismo, y permite localizar al trabajador permanentemente. Se debate si la finalidad del dispositivo es activar el protocolo de seguridad de la empresa en caso de emergencia, o bien, con dicho pretexto, simplemente fiscalizar la actividad del trabajador de forma invasiva de su intimidad y dignidad, decantándose el Tribunal por esta segunda tesis. La situación de riesgo psicosocial deriva de que ese aparato de última tecnología debe estar controlándose por parte del trabajador incluso en su domicilio familiar, reserva de su esfera personal y privada, trasladándose al trabajador una responsabilidad fuera de su jornada laboral, lo que puede generarle un plus de responsabilidad, tensión y preocupación añadida al puro desempeño de su prestación laboral en la jornada laboral.

Sin embargo, otra doctrina judicial está determinando, en relación con temas tan candentes como la videovigilancia o el control de dispositivos móviles, que los derechos constitucionales pueden plegarse con facilidad ante el ius variandi empresarial y su poder de dirección disciplinario. Tal es el caso de la Sentencia del Tribunal Constitucional de 3 marzo de 2016, en el caso Bershka, en la que el Tribunal Constitucional ha modificado su doctrina anterior, declarando válida la represión de una trabajadora dependienta a la que se despide mediante la prueba de la grabación de una cámara instalada en la empresa, cuyo funcionamiento no es notificado a los trabajadores, no solicitándose tampoco su consentimiento informativo. 
También en relación con otro derecho fundamental, el de huelga, recogido en el artículo $28.2 \mathrm{CE}$, se están produciendo cambios inquietantes en la doctrina constitucional. Frente a la doctrina anterior, va modulándose recientemente la admisibilidad del esquirolaje tecnológico en base a determinados supuestos de hecho. Así, en la STC de 2 de febrero de 2017, del caso Telemadrid, comprobamos como la tecnificación puede resquebrajar este derecho fundamental. En este caso, el uso de medios técnicos a disposición de la empresa no vulnera el derecho de huelga, se dice, cuando los trabajadores que acuden a trabajar realizan sus funciones habituales sin sustituir a los huelguistas, pero activan los recursos tecnológicos existentes para que el servicio se siga prestando. Parece indudable que, de confirmarse este viraje del Tribunal Constitucional, cada vez será más sencillo eludir las consecuencias de no producción de una huelga utilizando la tecnología disponible.

La actitud jurisprudencial, desvaída en cuanto al compromiso con los derechos fundamentales, es predicable incluso del Tribunal Europeo de Derechos Humanos (TEDH), que en ámbito laboral parece querer mantener una equidistancia funambulesca entre las partes, por la ausencia de referencias firmes a la prevalencia de aquéllos sobre los derechos, aun legítimos, empresariales derivados del control laboral. Así, la Sentencia de este Tribunal de 12 enero 2016, caso Barbulescu vs Rumania. Las expectativas de privacidad sobre la correspondencia del trabajador, también en el trabajo, para el tribunal, habrían quedado anuladas por las normas previas de la empresa, taxativamente prohibitivas de cualquier uso particular de los dispositivos móviles de la empresa.

Estas son expresiones arquetípicas de la colisión y ponderación de derechos alexyana, que deberían haberse decantado, a mi juicio, hacia la protección de los principios más relevantes en su infiltración ética de los derechos fundamentales. Éstos penden finalmente en cuanto a su efectividad de la simbiosis o separación estanca que se haga de los derechos de ciudadano con respecto a su condición de trabajador, y a la modulación requerida. No es ocioso recordar que ya la Sentencia del Tribunal Constitucional 88/1985, de 19 de julio, refería que el trabajador no debe orillar ni aparcar sus derechos cuando cruza la puerta de la empresa, pues el hecho de formalizar un contrato de trabajo «no implica en modo alguno la privación para una de las partes, el 
trabajador, de los derechos que la Constitución le reconoce como ciudadano». Y ello porque «las manifestaciones de «feudalismo industrial» repugnan al Estado social y democrático de Derecho.

\section{LAS GARANTÍAS CONSTITUCIONALES. LA DIGNIDAD DEL TRABAJADOR.}

Puesto que, finalmente, los límites a los abusos del control y vigilancia empresarial en relación con los nuevos modos de producción tecnificada, tendrán de nuevo el bastión de la dignidad humana, positivizada en rango máximo en el artículo $10 \mathrm{CE}$ y que posee además connotaciones metajurídicas, como valor de la persona y límite de ejercicio de otros derechos.

La dignidad es un principio jurídico, pero también es un valor y un derecho que debe ser protegido, como encarnación del respeto exigible, también en las relaciones sociales. Es la exigencia de ese respeto y estima en el orden laboral el que puede ser mancillado con el tecnoesclavismo que denuncio.

La dignidad se define como la consideración frente a los demás de la esfera de libertad y la identidad del ser humano como portador de derechos, valores y rasgos inalienables frente a terceros o grupos de opresión. Es el derecho a la personalidad que despliega una batería de derechos irrenunciables.

Este planteamiento nos conduce claramente hacia una dimensión constitucional del derecho del trabajador a su seguridad y salud laboral, también por la vía, claro está, de las manifestaciones necesarias del derecho al trabajo del artículo $35 \mathrm{CE}$, pero sobre todo del artículo 15, por su carácter de derecho fundamental que, si bien no integraría todos los casos de riesgo laboral mal resueltos por la empresa, sí los que comportaran un peligro grave y cierto para la integridad del trabajador, ya sea física o como sufrimiento moral.

\section{CONCLUSIONES.}

En un mundo industrial en ebullición, donde la eliminación de costes de intermediación y salariales parecen prioritarios, se financiariza la economía, se deslocalizan las empresas, y la hiperglobalización de mercados hace difícilmente aprehensible un 
marco estable de regulación laboral respetuoso con la dignidad del trabajador, la variable adicional de una maquinización crecientemente sofisticada y el propio uso para la industria de la inteligencia artificial, hace creíble una amenaza antigua que hasta ahora no se ha cumplido: la sustitución del trabajo humano por las máquinas.

Robotización, envejecimiento, revolución industrial 4.0, teletrabajo, son desafíos a los que debe darse respuesta con las armas del Derecho del Trabajo. Sin duda, es posible que el futuro consolide un cambio de paradigma, en el que el trabajador "fordiano", lejos de ser un referente de transacción en el conflicto social, se convierta en reliquia del pasado. Pero nuestra disciplina, adaptándose en lo necesario a los retos, deberá responder con los instrumentos adecuados, de tal manera que no se pierda el objetivo de protección de una relación jurídica laboral justa y equilibrada, sin iniquidad ni dominación, y con el respeto a los derechos constitucionales y a los instrumentos internacionales.

Mientras tanto, periodos de crisis manifiestan ya figuras elusivas y escapistas del marco garantista del Derecho del Trabajo. Este reto debe ser abordado con una actitud valiente y sin prejuicios. De lo contrario, el desequilibrio real en el ámbito subjetivo, empleador y trabajador, se incrementará exponencialmente, y además colectivos crecientes quedarán marginados de la tutela del ordenamiento jurídico laboral.

El panorama de una disponibilidad absoluta del trabajador, casada con una incertidumbre igualmente relevante sobre su estabilidad laboral, aparece ya como realidad incipiente. Tendremos por ello un nuevo estatuto de trabajador «transparente» y constrictivo, con un blindaje «licuoso» y endeble de protección de sus derechos.

La potencia telemática de control y vigilancia del empleador está creciendo ya exponencialmente cuando los instrumentos de trabajo son dispositivos técnicos. Es el tecnoservilismo, la alienación del siglo XXI, que está germinando en algunos casos en un hostigamiento o acoso institucional.

En nuestras manos tenemos el poder de evitarlo mediante un Derecho del Trabajo equilibrado que intermedie en el conflicto de los grupos de interés, sin claudicar ante la lógica económica que pretende un estatuto del trabajador al servicio únicamente de la 
conveniencia de la productividad maximizada y del abaratamiento de los costes, con interés secundario por los derechos de la persona, como parte de un contrato de trabajo.

Para ello es preciso, «lege ferenda», un reconocimiento más profuso y concreto de los derechos y obligaciones laborales, abordándose su conectividad con los riesgos de la tecnificación, la vigilancia empresarial y los abusos de la prestación laboral derivados de los medios informáticos. Esta actualización normativa debería abordarse también en una reforma constitucional en la que se protejan los derechos informáticos de una forma más sustancialmente garantista y con expresa referencia a los abusos hacia arquetipos vulnerables, como los consumidores o los trabajadores.

En todo caso, para el caso de que sean certeros los diagnósticos que aseveran que el dilema del futuro no será el desplazamiento de unos trabajos por otros sino el de supresión neta de oportunidades laborales, quiero recordar que tenemos campos inexplorados en nuestro país que deberían ser objeto de tratamiento en el diálogo social del futuro, como el reparto del tiempo del trabajo y una formación de calidad y especializada para adaptarse a los brutales cambios que se van a producir sin pausa.

\section{REFERENCIAS BIBLIOGRÁFICAS.}

Bauman, Z. (2000). La modernidad líquida. México: Fondo de Cultura Económica.

Braverman, H. (1974). Labor and monopoly capital: The degradation of work in the twentieth century, NYU Press.

Chul Han, B. (2011). La sociedad del cansancio. Barcelona: Herder.

Frey, B. y Osborne, M. (2013). The Future of Employment: How susceptible are Jobs to computerisation? Oxford Martin School.

Keynes, J.M. (1930). Economic Possibilities for our Grandchildren. Yale Economics.

Lafuente Pastor, V.P., (2016). La reforma laboral de 2012: un espejo roto de la flexiseguridad europea. Tesis doctoral. Universidad de Zaragoza.

López González, J.C. (2017). El contexto social: las nuevas realidades en las formas de trabajar. Madrid: Jornadas CEOECGPJ. 
Mella Méndez, L. (Dir.) (2017). Los actuales cambios sociales y laborales: nuevos retos para el mundo del trabajo: Pieterlen (Suiza): Peter Lang, International Academic Publishers.

Rifkin, J. (2010). El fin del trabajo: nuevas tecnologías contra puestos de trabajo. El nacimiento de una nueva era. Barcelona: Paidós Ibérica.

Rimbau-Gilabert, E. y Myrthianos, V. (2013). Trabajo contingente y productividad en los servicios. IN3 Working Paper Series, Universitat Oberta de Catalunya. 